\title{
Monitoring and continuous Commissioning of new and existing Buildings
}

\author{
Teriö Olli ${ }^{1}$, Räinä $\mathrm{Ilkka}^{1}$, Hienonen Markku${ }^{2}$, Kääriäinen Hannu ${ }^{3}$, and Kauppinen Timo ${ }^{4 *}$ \\ ${ }^{1}$ City of Oulu, Building Supervision Office Solistinkatu 2, PO Box 38, 90015 Oulu \\ ${ }^{2}$ The Finnish Society of Building Inspectors RTY, Kettutie 2, 00800 Helsinki \\ ${ }^{3}$ Oulu University of Applied Sciences, Kotkantie 190250 Oulu, PO Box 222, 90101 Oulu \\ ${ }^{4} \mathrm{~T}: \mathrm{mi}$ Mutsal, PO Box 60, 90651 Oulu, Finland
}

\begin{abstract}
In the building industry, the quality control practices during the design stage, implementation, introduction and use varies. Also, the owner's project requirements may vary. The instrumentation, measurements and the control options are different. The final product of the building process is the indoor environment. When evaluating the need of renovation of existing buildings and to control the performance of a new building, certain procedures are needed. Building automation system collects information for control of the building systems and for the users and stakeholders. The validity of the system depends on the level of instrumentation, data processing and reporting. The level of measurements can't be equal in all buildings. Apartment houses does not need such installations than e.g. hospitals. It is obvious, anyhow, that the data collection, processing and reporting need to be improved. The new sensors and data transfer technologies give a better opportunity to do so. In new buildings it is possible to measure the performance of certain structural details and compare the results with the models. The actual performance does not necessarily fit the planned because there can be always some differences and deficiencies after construction phase. The planning of renovations must be based on condition assessment, and normally there are various measurements carried out and also documents are checked, if there are measurement records available Because the performance and indoor conditions are the sum is the integration and function of all the systems together, measurements can reveal deficiency and inefficiency of building systems.. In this presentation some examples and measures are introduced, based on the city of Oulu, Finland. The advantages of commissioning-type monitoring are discussed. The key point is to have proper measurements and especially proper reporting.
\end{abstract}

\section{Introduction}

The need for renovation of buildings in Finland is due to changes in use, general aging and wear of buildings and their systems, deficiencies in the ventilation system or building systems in general, structural damage and indoor air problems, which are almost always due to a combination of factors. The base cause of indoor air problems may because of solutions already made at the design stage and quality deviations during the construction phase.

There have also been problems with new or newer buildings. Attention has been paid to prevent moisture damages during construction.

Moisture and mold damages are at the root of a number of indoor condition problems, but the causes for their occurrence can be due to a variety of factors, but mainly to internal and external moisture transfer to structures and moisture damage of building materials. Damages cause health problems and costs [1].

\footnotetext{
Corresponding author: tkk@mutsal.fi
}

The basic performance is defined according the building regulations. In addition to the degrees, the customer of the new building or renovation defines (or should define) its own performance requirements. Public building supervision office issues building permits and inspect plans. During the construction process, different quality assurance and commissioning procedures are in use. Still, the end result is not always what you want it to be - the building should work "as designed". The functioning of the building and the performance targets set for it can be verified during the design, construction and operation phases. Systematic quality assurance is called by the term " $\mathrm{Cx}$ - Building Commissioning". Commissioning based on measurements and continuous monitoring is called "Monitoring Based Commissioning - MBCx". However, there is no common and sufficiently consistent practice. Building companies and engineering office have their own applications. Individual procedures have been developed, for example to prevent moisture damage (DryChain10), which is becoming more common [2]. Building supervision 
offices in major cities are harmonizing interpretations of new building regulations [3]. Extensive programs have been launched or implemented by the authorities [4], [5] and also damage investigations [6], [7], [8]. Current sensor and communication technology enable the monitoring of key performance factors of a building and its systems. The measurements connected to the building automation system are not always sufficient for property management, and there are also shortcomings and improvements in data storage and reporting.

\section{Cx-Building Commissioning}

\subsection{What is building commissioning?}

Commissioning means, in general, that the owner`s project requirements (OPR) are well defined and they can be monitored by key performance indicators (KPIs), in a way that the performance of buildings is verified and the building meets the requirements. This will be carried out by different means, for instance by measurements, using checklists, calculations, modelling and monitoring so that the procedure is systematic [9], [10].

In the process and manufacturing industry the quality and features of the final product are verified during the process and when the product is completed

In building industry, one can say that the methods of commissioning vary widely, even quality control procedures are in use.

\subsection{Monitoring based building commissioning}

Remote control of buildings is an increasing trend in facility and energy management. Operation centers, either local or nationwide, even internationally operated, can collect enormous amount of data from the buildings and can give feedback for the users. In energy and facility management the term "management by information" describes the concept which in best case can optimize the performance of a building and energy and facility management costs. This also must mean also change of design intents, practices, and even how we should think. The procedure is called Monitoring Based Commissioning (MBCx) [11]. In many countries the building owners or facility managers have outsourced the data processing to cloud-service based companies, which collects and analyzes the data to useful information for the customer.

\subsection{Reporting}

The purpose of the measurements and monitoring is to provide useful information to various parties for the control and adjustment of building systems and indoor conditions, but also for the facility and energy management. The mere collection of measured data will not serve anyone unless it is processed in a comprehensible form. The information generated by the building automation system and the single measurements should be processed so that it can be used to make facility management decisions. It is important that measurements are made at appropriate and correct locations with calibrated sensors. The measurement frequency must be appropriate, but the results can be processed and modified so that the users of measured data are not drowning into it. Often the checking and calibration measuring devices is overlooked.

Measurements of airflows and temperatures of ventilation systems is an example of how in some cases reliable results are not obtained. If the temperature of a school building's exhaust air is measured before the heat exchanger and there are several classes in the service area, the excess temperature due to one class load can be overlooked below the average temperature.

Commissioning procedures can be combined with Building information model (BIM), which will give good opportunities to evaluate alternative solutions and effects of measures.

\subsection{Future developments}

To improve the use of the building automation system it is important that the measurements and reporting forms are planned in early stage of the design process and the automation planner will do that in co-operation with other designers. SRI (Smart readiness Indicators) and the improved EPBD-regulations as well resilience demands will set new challenges to building monitoring.

\section{Risk factors of buildings}

\subsection{Some typical defects}

The following is a list of some typical deficiencies or defects found in buildings. These cases can partially be applied to the new buildings, too [12].

- Uncontrolled underpressures and negative pressure differences causes air leaks through structures and their joints (old buildings are not airtight)

- There are problems with risk structures, which are now fairly well known, e.g. low-lying foundations, moisture damages

- The systems are not integrated to operate well

- Ventilation system contains fibers, mineral wool in sound insulation, wool fiber bonding hardens and allows for fiber detachment - damage of the floor covering, mainly of plastic carpets glued on a damp concrete slab

- Insufficient performance of ventilation, clogged air, insufficient room air quality

- Errors in operation and maintenance

- The sum of the above factors

\subsection{Risk factors of HVAC-systems}

The following topics, especially of HVAC-systems and structures, have not been adequately addressed. 
- The devices are not operating properly

- Malfunctions

- Devices cannot be used properly

This is partly due to the complexity of the systems and the lack of training. Depending on the building type, the share of building services (HVAC-systems) can be $40 \%$ of the total building costs.

Even the share of heating energy decreases, the share of electricity is increasing. It is very important, that submetering of electricity will be increased, because otherwise it is difficult to evaluate the distribution and use of electricity, and by the same to plan energy saving measures. Also, in case of multi-energy solutions measurements have shown that the consumption has been bigger than calculated - more detailed measurements would help to find the performance problems.

The improved level of instrumentation and reporting could reduce problems, but it will not completely remove them.

\subsection{Typical actions}

- Very few measurements are used during construction stage. Humidity measurements, thermography and air tightness measurements, etc. are used

- Pressure condition meters and room-specific indoor condition measurements are increasingly installed in buildings.

- Ventilation devices are monitored by sensors

- Room-specific sensors for the users, the ventilation is defined by the user load

- Outdoor air sensors (solar and temperature sensors) provides information for control

\section{Various guidelines}

\subsection{Background}

An example of guidelines and also of what the authorities can do is the building supervision office (BSO) activity. BSO Oulu has created quality cards for the use of their customers. The following chapter introduces the quality control card "Building commissioning in apartment houses retrofitting project". It includes tasks, checklist and measurements

In the beginning the usage and utilization of the card is presented (figure 1).

"One of the basic goals of a renovation project is to have the necessary plans ready and the building to function after the repairs as originally planned. Relevant decisions regarding performance, inspections and measurement shall be carried out regularly as the project proceeds. At the commissioning stage, a collective investigation is carried out to ensure completion of necessary procedures and a maintenance plan, based on the handover material, shall be drawn up for maintaining the value of the building and keeping housing costs reasonable."

The cards can be implemented, in addition to ensuring performance, as a check-list for planning various stages of a renovation project. The purpose of these cards is to guide the renovation project onto the right track and stay that way till its completion. Use of the cards is, however, voluntary. They complement the Building Control Services' building permission and inspection processes.

\subsection{Commissioning plan for retrofitting an apartment block}

The content and the structure of the publication is as follows:

1. Background information

2. Needs assessment and property condition assessments

3. Design guidelines and contracts

4. Groundwork, building envelope and spaces

5. Heating and heat distribution, water supply and sewerage installations

6. Ventilation and indoor climate

7. Electrical installations, telecommunications and lighting

8. Building automation and control

9. Acceptance inspection, commissioning and handover material

10. Continuous assurance of operation

\subsection{Target definition and building condition assessment}

Purchaser's targets shall be entered in the definition phase. A summary of measures:

Renovation programming and facility management plan

Establishment of energy-efficiency target

- Heating method and renewable energy

- Building heat loss and energy rating

- Specific heat loss of building external envelope

- Efficiency in heat recovery

- Premises implementation profile

- Ventilation system`s SFP rating

Establishment of indoor climate targets

- Thermal conditions

- Air quality

- Lighting

- Building material emission

- Air tightness

- Ventilation

- Pollution transfer

- Moisture performance 
Other points to be considered:

- Accessibility

- Fire protection

- Acoustic environment

- Operational safety

- Water and sewerage equipment
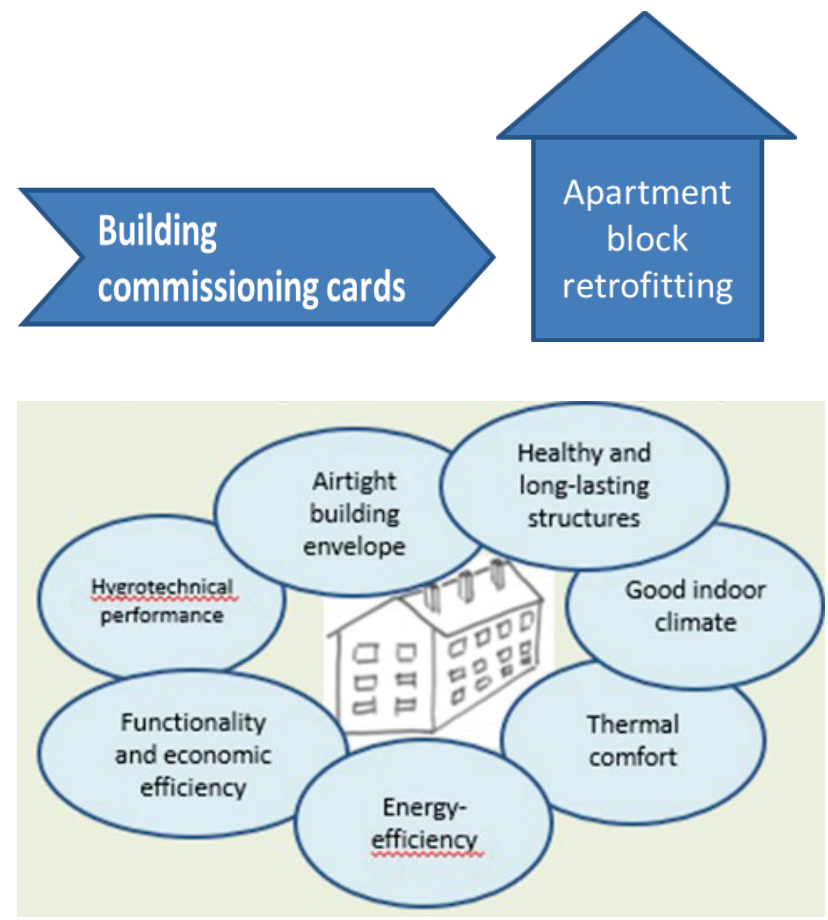

Fig. 1. The topics of retrofit

\subsection{Typical energy repairs in residential buildings}

- Improvement of airtightness

- Additional insulation to the roof slab

- Additional insulation of external walls while repairing the external cladding

- Change of windows

- Installation or boosting of heat recovery from ventilation

- Installation of heat pumps

- Switch over to more efficient household appliances

- Reduction of indoor temperature by cutting down draught or so-called "cold radiation"

- Basic adjustment of heat distribution network

\subsection{Acquisition of source data for planning}

- Construction technology condition survey

- Analysis of asbestos and harmful substances

- Condition survey of thermal, water supply and/or drainage installations

- Condition survey of electrical installations

- Hydrological condition survey
- Thermal imaging (leaks and thermal bridge)

- Leakage measurements, tracer tests

- Indoor air survey, microbes, VOC (Volatile Organic Compounds), radon

The next chapters are dealing with

- Design guidelines and contracts

- Groundwork, envelope and spaces

- Heating, heat distribution and

- Water supply and sewerage installations

- Ventilation and indoor climate

- Electrical installations, telecommunications and lighting

- Building automation

- Acceptance inspection, commissioning and handover material

- Continuous commissioning

\subsection{Continuous commissioning}

The contents of the card will be examined in more detail in the Continuous Commissioning section. Building sustainability, energy-efficiency, good indoor air and moisture management require continuous monitoring and supervision. Supervision safeguards both comfortable and healthy indoor environment and sustainability of the building. Supervision shall find equilibrium between remote supervision and monitoring visits at site. Also, faults reported by residents provide valuable information promoting functionality and performance.

Building management and building management plan are the backbone of continuous assurance of operation. These two-take care of not only operation but also preserving the value of the building. Regular inspections of the condition of the building are particularly important.

\section{Monitoring building systems}

- Compatible operation of systems; ventilation, air quality, heating and cooling

- Supply air stops in sub-zero temperatures, thawout periods for air source heat pumps

- Prevention of simultaneous heating and cooling

- Alarm plans for malfunction diagnostics of controls

- Remote monitoring (owner / service)

There is also list of organoleptic inspections and Examples of annual inspections. In table 1 other longerperiod inspections are introduced.

The overall commissioning (in Finnish: ToVa) procedure is in figure 2 . 
Table 1. Targets of Inspection

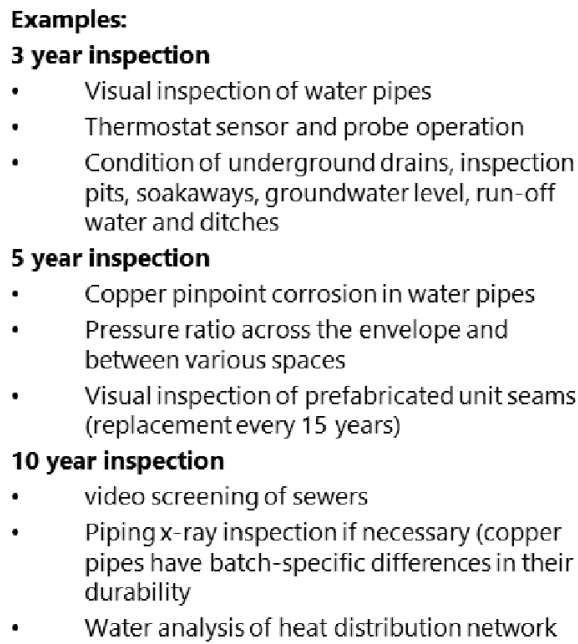

- Copper pinpoint corrosion in water pipes Pressure ratio across the envelope and between various spaces

- Visual inspection of prefabricated unit seams (replacement every 15 years)

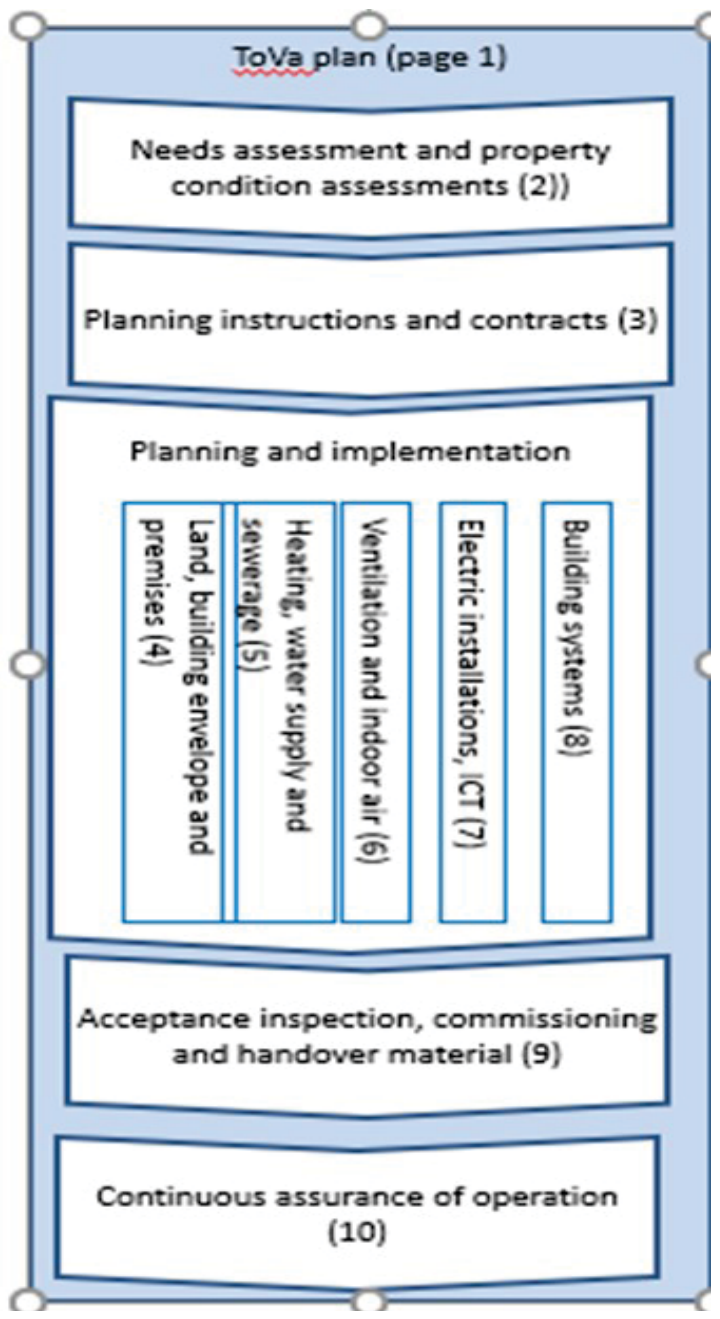

Fig. 2. The systematics of building commissioning procedure

\section{Experiences from the field practice and training}

The association of building supervisors has worked in cooperation with the biggest cities to create consistent practices on how to interpret building regulations and degrees. The main responsibility of BSOs in Finland is to control that houses will be built according to law, rules and city plan.

Now there is an ongoing national updating education of building inspectors - RVK 3 program. The new education program for existing building inspectors or persons who are aiming to be inspector in Finland

\section{Goal of the program}

-Update the knowledge of building inspectors to respond most important actual challenges

-Become familiar with new statutes/codes and instructions

- Give basic competence to person who are aiming to become building inspector.

-Give deeper knowledge to inspector in his own know-how area

-Utilizing best experts in Finland - as keynote speaker in every part of program

- Focus is always what building inspector should know and will need in his or her daily work!

A new department of Civil Engineering has also been established in University of Oulu. One professorship is "Indoor environment" which focuses indoor environment and building physics studies and education. The new department has also a supporting organization, Arctic Construction Cluster Finland [14].

\section{Conclusions}

Building quality assurance is a constant issue. In Finland, moisture and mold damages of buildings and indoor air problems have emerged in recent years. It doesn't mean they didn't exist before. There have been problems with both the new and the old building stock. Most of the building stock was built from the $60 \mathrm{~s}$ to $80 \mathrm{~s}$. Particular attention has been paid to public buildings such as schools, day care centers and other service buildings, such as office buildings and police stations, for example. The state, authorities and various communities have launched and realized programs in aim to identify and improve internal environment. At the municipal level, policies have been developed to identify and prevent damage and problems caused by indoor conditions. Renovation planning has been developed for existing buildings of indoor problems. However, there are numerous examples of indoor air repairs that have not led to the excepted result. Despite the repairs, problems still persist. The individual reasons for this are case-by-case and often one significant factor as the cause of indoor air problems cannot be named, but a combination of several factors. For example, repairs may 
be limited to defects in structures, even though the performance of a building is the sum of the interaction between the building's systems, structures and building services, and the operating conditions.

The outcome of repairs can be affected by lack of input data, lack of information and available budget Comprehensive mapping and planning are key to a successful repair. Inquiries carried out by various actors, companies and authorities have revealed a lack of information on building physics. Renovation, facility and space management are still under-represented in education and training at various levels in the civil engineering and real estate sectors, although progress can be seen. Similarly, building diagnostics and research and interpretation of indoor air symptoms need further development.

When determining the performance of a building, it is important that the performance requirements for the building, the definition of performance and the performance factors, both in new and renovation sites, are clearly stated, depending on the purpose of the building.

In order to monitor performance during the construction process and during operation, a performance assurance procedure is required, which is validated during construction and operation, as well as through appropriate measurements and reporting. The building automation system and measurements in buildings should also serve facility management and energy efficiency monitoring. Current sensor and communication technology make this possible, but requires to define measurements and monitoring, as well as proper instrumentation. Measurements must be calibrated at regular intervals. Monitoring based continuous commissioning improves the costeffectiveness use of the building, but there are still gaps in the building instrumentation development guidelines. There is a need for better definitions of key performance factors. The key question is how do you want the buildings to perform as designed and how to ensure their functionality. Nowadays, an increasing number of building projects are based on a life-cycle model, whereby monitoring the life-cycle performance of a building has a key role. Also, the changes in EPBD, especially the demands for building automation systems will put the pressure to improve the monitoring. The trend to create SRI is another driving force to have a better performance verification system.

\section{References}

1. Reijula, K \& al (2012). Rakennusten kosteus- ja homeongelmat. Eduskunnan tarkastusvaliokunnan julkaisu 1/2012. (Damp and Mold problems of Buildings, publications of Parliament of Finland, Audit Committee). ISBN 978-951-53-3454-1 (nid.), ISBN 978-951-53-3455-8

2. http://kuivaketju10.fi/ (https://www.rala.fi/english/), Rakentamisen laatu RALA r.y. (The Construction Quality Association)
3. https://www.pksrava.fi/asp2/default.aspx (Rakennusvalvonta Helsinki-Espoo-Vantaa Kauniainen/Building Supervision of Helsinki), https://www.hel.fi/kaupunkiymparisto/en/

4. www.vnk.fi/terveet-tilat-2028 (Program of Prime Minister`s Office)

5. https://hometalkoot.fi// (see also https://www.hengitysliitto.fi/en, The Organisation for Respiratory Health)

6. Weijo, I, Lahdensivu, J, Turunen, T, Ahola,S, Sistonen, E, Vornanen-Winqvist, C, Annila, P. Kosteus- ja mikrobivaurioituneiden rakennusten korjaus (Renovation and repair of buildings with moisture and microbial damage), Publications of the Ministry of the Environment.2019:18. ISBN: 978952-361-025-5, ISBN: 978-952-361-024-8 (PDF).

7. Pitkätranta, M. Rakennuksen kosteus- ja sisäilmatekninen kuntotutkimus (Building Moisture and Indoor Air Quality Assessment), Environment Guide 2016, Ministry of the Environment, Department of Built Environment. Rakennustieto Oy, 2016. ISBN 978-952-11-4625-1. www.rakennustieto.fi, http://julkaisut.valtioneuvosto.fi

8. see e.g. Avaimet terveelliseen ja turvalliseen rakennukseen (AVATER). Valtioneuvoston selvitys- ja tutkimustoiminnan julkaisusarja 44/2017. The keys to healthy and safe construction (AVATER) Summary report. Publications of the Government's analysis, assessment and research activities 44/2017. Prime Minister's Office, 25.4.2017

9. ASHRAE Guideline 0-2005, The Commissioning Process. American Society of Heating, Refrigerating and Air-Conditioning Engineers, Inc.ISSN 1049894X

10. Visier, J.C. (ed). IEA Annex-40. Report 1. Commissioning overview. Commissioning tools for improved energy performance. Results of IEA ECBC Annex-40.

11. Kauppinen, T, Hienonen, M. Monitoring Based Commissioning (MBCx) in Energy and Facility Management. BauSIM2016, September 14-16, 2016, Technische Universität Dresden, Germany. pp. 260-266 in Conference Proceedings of Central European Symposium on Building Physics CESBP 2016 / BauSIM, ISBN (E-Book): 978-3-8167-97982, Fraunhofer IRB Verlag, Stuttgart

12. Private communications, Kääriäinen, H, Oulu University of Applied Sciences, Räinä, I, BSO Building Supervision Office, City of Oulu.

13. Quality cards and interpretations, City of Oulu, Building Supervision Office, https://www.ouka.fi/oulu/rakennusvalvonta/laatukor tit-ja-tulkinnat

14. www. http://www.rakennusklusteri.fi/about 